\title{
Conceptualising (dis)advantage in South African higher education: A capability approach perspective
}

\author{
Oliver Tafadzwa Gore ${ }^{1 /}$ and Melanie Walker ${ }^{2}$ \\ ${ }^{1}$ North-West University: Education and Human Rights in Diversity Research Unit \\ ${ }^{2}$ University of the Free State

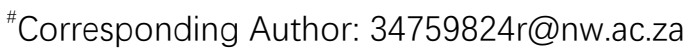

(Submitted: 28 January 2020: Accepted: 22 October 2020)

\begin{abstract}
Higher education policy in South Africa uses the concept of 'historically disadvantaged' to address inequities and inequalities. Disadvantage specifically refers to black students who are marginalised in higher education due to structural factors associated with the apartheid legacy of segregation. In this paper, drawing from the capability approach, the authors argue that (dis)advantage can be better understood in terms of students' capabilities, functionings, and agency, which go beyond race to address other forms of oppression like class, gender and related individual factors. Students with a wider capability set and agency to convert resources into capabilities and functionings are deemed advantaged in comparison with those who have a narrower capability set and lack agency. Based on theory and empirical findings, this paper offers a complex, multidimensional and nuanced conceptualisation of (dis)advantage to understand practical interventions in higher education. The findings show that foregrounding race in addressing disadvantage is limiting and policy should therefore provide opportunities to all students for them to succeed.
\end{abstract}

Keywords: capability approach, (dis)advantage, higher education, inclusion,

\section{Introduction}

Policy in South African higher education uses the concept of 'historically disadvantaged' to address inequities and inequalities. The former concept specifically refers to black students. For example, section 2.2.6 (c) of the Education White Paper 3 of 1997 views black students as financially disadvantaged and underscores funding to support their university education (Department of Education, 1997). Furthermore, section 3.2.5 of the White Paper 3 of 1997 recognises academic disadvantage for black students from poor-quality schools who enrol at universities without adequate preparation. Although it is clear that policy racially defines 'disadvantage' and that there have been significant redress gains (not least in the headcount of black students) since 1994, inequality and social injustices still persist in South African higher education. Students' success is still skewed along racial lines. For example, throughput rates for 
African students were 55\% compared to $65 \%$ for white students in three-year degree programmes in 2016 (Council on Higher Education, 2018). This raises the question whether using race only in addressing 'disadvantage' is sufficient. Besides it being difficult to monitor and evaluate intervention projects within and across universities, lack of clarity on what disadvantage means at policy level could result in universities having different interpretations of the policy and targeting aspects that policy did not intend to (Leibowitz and Bozalek 2015). This might not bring about the desired changes in higher education.

Higher education policy has been criticised for leaving the definition of 'disadvantage' open. As regards the funding earmarked for academic support programmes (Department of Education 2006), for example, institutions and their faculties adopted different definitions in their academic support programmes. Leibowitz and Bozalek (2015) explain that the concept of disadvantage was not defined in circulars that informed universities about the funds resulting in universities adopting different definitions of disadvantage. Although in this context, the White Paper 3 of 1997 (Department of Education, 1997) intended to support 'a section of first-year entrants' (the majority of these students continue to be black low-income students), some universities admitted white middleclass students who have not qualified in other universities while others enrolled the black middleclass students without specific plans for those from low- income backgrounds (Leibowitz and Bozalek, 2015; 12). This shows that there are different interpretations of what 'disadvantage' meant for the universities, leaving the term open for misinterpretation and the subsequent exclusion of the black low-income students whom policy intended to target in that academic development programme.

Besides the term being open to misinterpretation, the use of 'disadvantage' for interventions has not resulted in desired changes in higher education partly because of its focus on students while ignoring the structural inequalities that marginalise them in universities and society. Bozalek and Boughey (2012) explain that concentrating on black students while neglecting the teaching practices and the unfriendly institutional cultures and racism that alienate black students, especially in the historically white universities, contributes to ineffective interventions in higher education. Furthermore, policy 'misframes' lecturers and universities through holding them responsible for transformation, which diverts attention from the entire education system that fails to disrupt the historical, cultural, and economic inequalities (Bozalek and Boughey, 2012: 697). Therefore, to effectively address 'disadvantage', a comprehensive package that addresses both structural and individual factors is needed in the design of interventions.

If the definition of 'disadvantage' remains crude, 'the course of policy implementation may run counter to planned intentions' (Council on Higher Education, 2004:37). Hence, redefining the meaning of 'disadvantage' in the context of higher education is crucial in establishing other underlying factors that affect students in addition to race (Soudien 2010) and how these factors interact. Internalising the problem of academic exclusion to individual institutions is one of the ways policy 'misframes' higher education (Bozalek and Boughey, 2012: 698). This 'misframing' diverts our attention from questioning the effectiveness of policy in redressing inequality and 
social injustices. It is, therefore, necessary to reconceptualise the concept of 'disadvantage' to better inform interventions for equal opportunities in access, participation, and success in South African higher education and to reduce inequality in this context.

In the light of the above, this paper offers a conceptualisation of '(dis)advantage' through a capability approach lens. It argues for a more complex and multidimensional conceptualisation of the concept other than the exclusive use of race. The capability framework and key terms capability, functionings, agency, and conversion factors - are discussed to present a more nuanced understanding of advantage. Thereafter, capability-inspired dimensions of '(dis)advantage' are highlighted based on the literature and empirical findings.

\section{The capability approach}

The capability approach (Sen, 1992, 1999) was developed as a critique of utilitarian approaches that use income, resources, and happiness as measures for relative advantage. Sen argued that, when one measures relative advantage, one should do so using the 'capability space' rather than income, resources, and happiness. For example, the use of income (Rawls, 1971) to measure relative (dis)advantage does not consider the difference between individuals and their capability to convert resources to achieve wellbeing (Sen, 1984, 1999). Someone with disabilities might need additional resources, or students from poorly resourced schools might need additional teaching support compared to those from high-quality schools. High-quality schools are former Model $\mathrm{C}$ schools and historically white schools that charge fees to pay for additional teachers; hence, they are better resourced than township and rural schools that do not charge fees. When measuring (dis)advantage, therefore, focus should be on the quality of life or wellbeing of individuals and not only on income. The capability approach is deemed appropriate for evaluating student (dis)advantage due to it being multidimensional and enabling interpersonal comparisons of dimensions that constitute individuals' wellbeing. Key terms in the capability approach are 'capability,' 'functionings,' 'agency', and 'conversion factors'. These terms are explained next.

\section{Capability and functionings}

Capability means an individual's 'real opportunities to achieve functionings' (Robeyns, 2017: 39). Capability is what is effectively possible - it implies an individual's opportunities to choose from available options, while functionings refer to actual realisations or achievements. Functionings are 'constitutive of human life' (Robeyns, 2017: 39). This means that they are the beings and doings that make for a good life - for example, having decent shelter, adequate food every day, transport, and participating in university learning and social activities. Students may also have capabilities, but for whatever reason they choose not to exercise them, or they may have 'hidden' capabilities they do not recognise as important for their university success. To understand a good student (human) life with dignity, we must understand functionings. Universities should create an environment where all students can develop capabilities to achieve educational functionings. Wolff and De-Shalit (2007: 8) refer to capabilities and functionings as 'dimensions of wellbeing', 
because they are reflective of one being advantaged or disadvantaged, for instance, through mental health, income, and social networks. We might identify these wellbeing dimensions bottom-up from students' experiences and voices.

\section{Agency}

Agency is central in Sen's (1999) approach, because he understands people as agents in their own lives and not as passive spectators of development programmes. In his conceptualisation, agency relates to one's power and willingness to influence one's environment in order to act towards one's valuable goals. Thus, for Sen (1999: 19), an agent is:

someone who acts and brings about change, and whose achievements can be judged in terms of own values and objectives, whether or not we assess them in terms of some external criteria as well.

Agency can include the ability of students to make choices and to take action in their studies so that they can graduate. Also, key to agency is our responsibility to determine our destination through making decisions, pursuing future goals, or changing our lives towards the things we have reason to value. Equally relevant is for individuals to be autonomous, selfdetermining, and able to challenge unfair systems (Cleaver, 2007; Nussbaum, 2010). Thus, agency means students being able to make their own decisions and to act (or not). The ability to exercise agency then reflects advantage (Walker and Unterhalter, 2007). Advantage entails the absence of obstacles that limit the agency of some students but not others.

\section{Conversion factors}

The capability approach integrates individuals and their agency with social arrangements through the mechanism of intersecting conversion factors. Sen (1999: xi-xiii) is clear that our agency 'is inescapably qualified and constrained by the social, political and economic opportunities that are available to us', so it is important 'to give simultaneous recognition to the centrality of individual freedom and to the force of social influences on the extent and reach of individual freedom'. Individuals have different real effective opportunities to turn their bundles of resources (material, policy endowments, such as fees-free higher education, and so on) into achieved functionings due to personal, social and environmental conversion factors such as social class, race, gender and geography as well as personal effort and resilience. The central issue is how capabilities (and the corresponding functionings) are distributed among diverse students and the complexity of this distribution across students' lives. When evaluating educational (dis)advantage, we thus need to ask the following question: 'Do some people get more opportunities to convert their resources [social and cultural capitals, talents and agency freedoms] into achievements than others, if so who, how, and why?' (Walker and Unterhalter, 2007: 134). Social capital constitutes the power and economic resources that students derive from their families, friends and schools, while cultural capital refers to middle-class students' familiarity with university expectations before their 
enrolment that allow them to fit in (Bourdieu and Passeron, 1977). Most low-income black students are disadvantaged in South Africa, as they lack these forms of capitals. Nevertheless, universities might not be able to address some the challenges students face as these are rooted in the structural factors. For example, poverty, belonging to a low-income family, and poor schooling contribute to the failure of these students to adjust and fit into the university environment. This implies that universities ought to be seen as part of a complex ecosystem, which should be considered in the current redress policies and future considerations.

The White Paper 3 of 1997 aims to increase access of black and female students and those with disabilities who have limited chances of enrolling at universities and to transform the institutional cultures especially in unfriendly historically white universities that resemble white and male domination (Department of Education, 1997). The White Paper 3 of 1997 also outlines the provision of funding to low-income, deserving students through the National Student Financial Aid Scheme (NSFAS) (Department of Education 1997). Recognising the poor schooling that most black students have had, higher education set out the provision of funding for academic support programmes in order to improve the performance of underprepared students. The above indicates that most black and female students are disadvantaged due to structural conversion factors, which continue to be experienced.

Personal factors (e.g., talent and academic skills), social arrangements (e.g., gender, support from peers, family members) and other structural/institutional factors (e.g., language issues, teaching arrangements, racism in society and the university setting) intersect to enable or constrain individuals' ability to realise their functionings. For example, most black students are disadvantaged through the intersection of racism in the society, universities (structural or institutional) and related individual factors. Individual factors include, for example, living far from campus without safe and efficient public transport (environment) and facing discrimination from well-off students based on the way one dresses and the food one eats (social). Conversion factors might work together to strengthen advantage effects and inclusion, or might reinforce disadvantage and exclusions. Our understanding of (dis)advantage can be further developed through adopting Wolff and De-Shalit's (2007: 121-122) concepts of 'fertile functionings', 'clustering of disadvantages', and 'corrosive disadvantage'. According to Wolff and De-Shalit (2007), the clustering of disadvantages refers to different levels or forms of disadvantage that are connected in worsening individuals' lives. Thus, disadvantage can have a cumulative effect on students' lives and may diminish their opportunities to graduate. Furthermore, 'corrosive' disadvantage is when the causes of the disadvantage are connected and may persist over generations (Wolff and De-Shalit, 2007). Both concepts are relevant in interrogating (dis)advantage in the South African context where black students experience intergenerational disadvantage linked to apartheid exclusions, including their mental sphere. It is, however, the case that most white families' incomes are stable because they have accumulated (some) wealth over generations and are mostly able to afford private and former Model $\mathrm{C}$ schools and university expenses because of their established material resources. This illustrates Wolff and De-Shalit's 
concept of 'fertile functioning', which means that functionings have multiplier effects in advantaging students.

\section{Incorporating concepts of the capability approach to explore (dis)advantage in higher education}

Sen (1992) uses the concepts of 'wellbeing freedom', 'wellbeing achievements', 'agency freedom', and 'agency achievements' to evaluate human development. These concepts can be developed into a framework to assess (dis)advantage in higher education (Walker and Unterhalter, 2007). It is important to note that the term 'disadvantage' typically labels black students who come from low-income backgrounds in the South African context. For the purposes of this paper, students are not considered as inherently advantaged or disadvantaged; rather, their circumstances operationalised through conversion factors that construct disadvantage. While personal effort and academic talent can play a role, they require a confluence of enabling circumstances. Moreover, while some students may not have the social and cultural capital universities look for, they may have linguistic and navigational capital that are valuable in other ways as forms of advantage, albeit not well-recognised by universities (Mathebula, 2019). These resources, however, are significant within supportive structures that are unracialised universities. Lowincome black students could struggle to fit into the university culture which resembles that of middle-class students; as such, they have limited capital on what is valued in the field of higher education. This is considering that their capital (resources) is derived from poorly resourced schools, families and communities, which, in a sense, are conditioned from the past (structural). Thus, low-income students are either enabled or constrained by structural factors, and their ability to exercise agency is conditioned (even though not pre-determined) by social structures. The term '(dis)advantage', therefore, recognises the deeper cultural enablements that lowincome black students bring to universities and the conversion factors at work. Moreover, '(dis)advantage' is used because of the possibility it offers to discuss and frame how the structure is enabling or disabling to some students and how students' valued outcomes compare with each other given that the capability approach evaluates (dis)advantage in the space of capabilities.

(Dis)advantage is thus conceptualised as having the opportunities to achieve education goals. The implication is that, for diverse students to have educational achievements (advantage), there is need to disrupt structural and institutional arrangements and address individual factors that constrain students to have opportunities in universities. Such a framework is helpful in evaluating students' experiences in university and specifically their wellbeing as well as the extent to which they are able to succeed (see Table 1 for the framework). (Dis)advantage and wellbeing are then coterminous.

In practice, capabilities as potentials are not visible when comparing individuals, unlike functionings which reflect what has been achieved. Thus, we must generally rely on functionings as a proxy for the capabilities being measured (Walker and Unterhalter, 2007). Sen (1992), however, argues that the use of functionings alone to measure (dis)advantage may yield insufficient information on how resources, opportunities and individual capabilities are 
distributed. Two students could have achieved the same functioning (an upper second-class degree) whilst they had access to varying resources and different conversion factors because of personal differences. The use of functionings alone does not provide any information about the resources and real opportunities the two students had to achieve the same result. It also does not tell us anything about the enablements or constraints each one faced during their studies. Because of the need to enrich our understanding of (dis)advantage, capabilities and functionings could be used to evaluate relative (dis)advantage. Comparisons of the functionings of students, at the same time making an interpersonal comparison of the capabilities extrapolated from their functionings, could be helpful in evaluating (dis)advantage.

Table 1: Understanding (dis)advantage through a capability lens

\begin{tabular}{|c|c|c|c|}
\hline $\begin{array}{l}\text { Opportunities/freedoms } \\
\text { at university }\end{array}$ & $\begin{array}{l}\text { Conversion factors } \\
\text { (intersecting) }\end{array}$ & $\begin{array}{l}\text { Achievements/ } \\
\text { functionings }\end{array}$ & $\begin{array}{l}\text { (Dis)advantage } \\
\text { (wellbeing) } \\
\text { Outcomes }\end{array}$ \\
\hline $\begin{array}{l}\text { Being able to respect and } \\
\text { appreciate other humans. } \\
\text { Being able to learn in the } \\
\text { field of study. } \\
\text { Being able to afford } \\
\text { university expenses. } \\
\text { Being able to participate } \\
\text { in university education, } \\
\text { e.g. freedoms to aspire, } \\
\text { having academic skills, } \\
\text { etc. (as a result of } \\
\text { opportunity). }\end{array}$ & $\begin{array}{l}\text { Structural elements, e.g. a } \\
\text { racialised/non-racialised } \\
\text { society, university culture, } \\
\text { university teaching, } \\
\text { funding policy. } \\
\text { Social factors, e.g. family } \\
\text { support, schooling, } \\
\text { finances. } \\
\text { Personal characteristics, } \\
\text { e.g. talent, attitude } \\
\text { towards schooling. }\end{array}$ & $\begin{array}{l}\text { (Educational wellbeing) } \\
\text { (e.g. having acquired } \\
\text { knowledge and academic } \\
\text { skills, passing and } \\
\text { graduating, personal } \\
\text { development, having } \\
\text { social skills). }\end{array}$ & $\begin{array}{l}\text { (Advantage) } \\
\text { Greater educational } \\
\text { wellbeing and increased } \\
\text { agency achievements. } \\
\text { (Disadvantage) } \\
\text { Lower educational } \\
\text { wellbeing and fewer } \\
\text { agency achievements. }\end{array}$ \\
\hline
\end{tabular}

Source: Adapted from Vaughan (in Walker and Unterhalter, 2007: 119)

The framework allows us to focus on the freedoms available to students. It also informs us about the conversion factors enabling or constraining students from having such freedoms; for example, personal characteristics, curricula, teaching arrangements, gender inequality, and students' special needs are essential areas to focus on when evaluating inequality in education (Walker and Unterhalter, 2007). When students have increased educational achievements (wellbeing and agency), they are likely to be advantaged. The converse is also true: fewer educational achievements (wellbeing and agency) contribute to disadvantage. 


\section{Capability-inspired dimensions of (dis)advantage}

This paper combines capability-inspired dimensions of (dis)advantage based top-down on the capability literature in the field of South African higher education and bottom-up on empirical data. Various lists of dimensions have been generated (e.g. Calitz, 2018; Loots and Walker, 2015; Mutanga and Walker, 2015; Walker, 2006; Walker, 2016; Wilson-Strydom, 2015). The selection of most of the items on these lists centred around student wellbeing. While Nussbaum's list (2000) is purely philosophical, prescriptive, and comprehensive, the other lists are grounded in evidence from student and/or teacher voices and literature. This paper contributes to dimensions specifically grounded in (dis)advantage as complex and multifaceted.

The empirical data were obtained from a case study of the University of the Free State (UFS). The UFS is a middle-ranked and historically white, Afrikaans-language university that presently enrols students from diverse backgrounds. Although transformation has taken place at the UFS through its Integrated Transformation Plan (UFS, 2017), the institution is conservative in many ways (Walker, 2016), with incidents of racism taking place periodically, for example, through violence that erupted between groups of white and black students during a rugby match in 2016 . During the time of the study, the UFS charged tuition fees and would not register students without receiving a payment for the tuition fees. This, however, changed with the introduction of free higher education in 2018, where students whose families earned below R350 000 per annum were no longer required to pay tuition and would receive financial aid from NSFAS.

We conducted 26 semi-structured interviews with volunteer students from four departments - Political Sciences, Psychology, Education Studies, and Business Studies and Agricultural Economics - purposively selected to ensure diversity. Ethical approval was obtained from the University of the Free State to conduct this study. Pseudonyms were used to protect each participant's identity. The participant group was diverse in terms of their gender, race, socioeconomic status, living arrangements at the university (living in campus accommodation or off campus) and schooling background. We collected biographical data of participants, namely family background, choice of university and degree programme, financial arrangements for the university, fitting into the university environment, teaching arrangements and aspirations. Based on other education-inspired dimensions and the empirical data that emerged from this research, this paper proposes 'capability-inspired dimensions of (dis)advantage' for university students from theory, other research findings and empirical data for further discussion and testing in other contexts. However, the proposed dimensions are not exhaustive or universal.

\section{(a) Affiliation}

The affiliation dimension comprises social relations and respect, dignity, and recognition. This capability refers to students' ability to form social networks with their lecturers and mentors for support (Walker, 2006), especially for the low- income black university students who left behind former social relationships when they migrated to stay on campus. This corresponds with Nussbaum's affiliation dimension - the capability of humans to show concern for others and 
joining social groups (Nussbaum, 2000). The significance of the dimension of affiliation is also seen in interactions across race, gender, and ethnic groups. For example, in her study on racism, Walker (2016) reported that both white and black students become thoughtful and aware of other students who are different from them after undergoing a leadership-for-change programme. Having a sense of belonging at the university is an essential aspect of affiliation. Nussbaum sums up that, "protecting this capability [affiliation] means protecting institutions that constitute and nourish such forms of affiliation' (Nussbaum, 2000: 79). The dimension of respect, dignity and recognition addresses the ways in which students treat each other and how academic staff perceive them regardless of their gender, ethnicity, religion, race, and language. Concerning language, most black students come from schools where English is spoken less frequently; yet, the opportunity to use the language of instruction proficiently is instrumental in enhancing students' respect and recognition (Wilson-Strydom, 2015). Kathleho accounts how he felt disrespected in class due to his inability to understand and speak English fluently:

We learnt using Sesotho in my primary and secondary schools, but I was now expected to write and speak using English at the university. To say the truth my English was very bad, and I was so uncomfortable to speak out my views in the classroom discussions because other students jeered at me. I also could not understand what the lecturers were saying in class. As a result, I lost confidence in my studies and failed some modules in my first and second years. (Kathleho: black male, Bachelor of Education)

The affiliation dimension also refers to students valuing being respected by others and by lecturers irrespective of their social class, race, ethnicity, and gender, amongst others. Choosing one's identity is another aspect that falls under this dimension and is related to the capability of being aware and critical of race and racism. Findings from student data reveal that race or racism still (dis)advantages students. Students in our study reported that the university was racialised, as demonstrated by the violence that took place between white and black students at a rugby match on the university campus:

I remember there was a rugby game last year and we were very scared for hours at our residences. ... Apparently, white students were looking for black students and beating them. We saw some black students who were passing by being punched and hit by sticks. These students did not even know what was happening at the rugby field. This was so scary. (Atang: black female, Honours in Psychology)

Although the UFS made efforts to reduce racism at the campus through promoting inclusiveness in classes, residences and other spheres of the campus (University of the Free State, 2018), the above incident is a reflection of the society from which the students come. Racial incidents at the university illustrate the deeper structural and cultural mechanism which continue to marginalise black students. Affiliation as a 'real potential' capability to be realised requires 
strong corrective justice in transforming the university through changing the beliefs and attitudes students bring in from their communities. Being respected and recognised by others - regardless of one's race, identity, language, gender, and class - is an important aspect of affiliation that can either promote or inhibit students from progressing in their studies.

\section{(b) Economic stability}

Economic capability is valuable because it enables the expansion of other capabilities. For example, according to Sen (1999) and Therbon (2013), resources and money are critical in the realisation of other capabilities. Though looking only at income is insufficient, having adequate financial resources is a vital condition for other capabilities to be realised. Therbon (2013) theorises that an increase in a person's resources to a certain threshold leads to the expansion of the existential dimension, which refers to personhood aspects such as respect, confidence, and participation, thus leading to wider and deeper capabilities. The absence of the necessary economic capability amongst students leads to disadvantage, whereas economic capability together with agency give students a greater chance to expand other capabilities.

The economic freedom dimension can be viewed in two ways: a) through students' finances, and b) by focusing on economic gains students can look forward to after graduation. Unequal participation in higher education has also been attributed to economic deprivation, as students continuously worry about how their parents are going to raise registration fees and money for basic commodities:

Most of the times I had to live without money for basic needs. I don't know how I actually went through those days. I was not having anything as my mother was struggling to raise the tuition fees especially during registration time. So many times, I had to borrow. So many times, I came to university hungry because I wanted to make something out of myself (Joline: black female, Political Sciences).

Although Joline completed her undergraduate studies, she dropped out before completing her honours degree, because she owed the university money. It is essential to consider this capability, as lack thereof affects students' realisation of other functionings. Joline could not complete her honours degree and graduate due to inadequate funds to pay her university debt. Additionally, students value income gains through getting employed after completing their degree programmes (Walker and Fongwa, 2017), often so that they can improve the lives of their families. Mosebi explains:

I have always wanted to get into business, and I decided to enrol for business management degree so that I learn the fundamentals of business. I am also in my final stage of studying a Chartered Accounts programme. These qualifications will open up employment opportunities for me and I will have an income to improve myself and my family. If I can work for maybe for the first 3 or 5 years after graduating, I would have obtained the working 
experience to help me start my own practise. (Mosebi: black male, Honours in Business Management)

While most of the participants were from low-income backgrounds, attaining a degree was regarded as a way of improving their financial income by securing employment. However, higher education does not automatically lead to employment and a good life. While the graduate unemployment rate is high and was $29.1 \%$ in 2019, having a degree positions a graduate better to get employed compared to 15 - to 24 -year-olds who do not have tertiary qualifications, among whom the unemployment rate was 63\% in the same period (Statistics in South Africa, 2020). However, historical inequalities continue to influence graduates' chances of getting employed, as race and the quality of secondary school they attended remain some of the predictors for graduate employment in South Africa in addition to the type of degree studied and university attended (Walker and Fongwa, 2017). Despite the affirmative action policies instituted to improve black youth access to employment, Walker and Fongwa (2017: 41) assert that black students have close to three times the chance of being unemployed compared to their white counterparts. White middle-class families tend to benefit from their parents' social networks to get part-time jobs or internships which ensure some working experience employers prefer (Bathmaker, et al., 2013). This suggests that socio-economic inequality is among the dimensions (dis)advantaging students, and this data should be captured and assessed when monitoring and evaluating interventions.

\section{(c) Autonomy and participation}

This dimension refers to students having the necessary capabilities to be autonomous, make decisions that matter to them, and being able to participate in the learning process. Making autonomous decisions about one's life forms part of the freedoms individuals should have in determining what they want to be (Sen, 1999). In higher education, evaluating whether students can make independent and informed decisions on the university at which to enrol, the degree programme to study and the career to pursue, helps us to understand if students are (dis)advantaged. While some students' ability to make choices is limited, adaptation is a form of disadvantage that limits some individuals from exercising their freedoms and agency (Robeyns, 2017). The interviews showed that some students were disadvantaged through lack of opportunity to make choices about what they wanted to pursue in their lives. Tshidi, who qualified for the social work programme that she wanted to pursue but ended up studying a Bachelor of Education at the UFS because the Funza Lushaka bursary she was awarded required her to do so. The Funza Lushaka bursary funds students studying Bachelor of Education. This bursary is not repaid but worked back as a teacher. She received the bursary after her teacher brought an application form for her to fill out during her matric year.

I didn't really choose that degree programme. I had to do Education because the bursary funds that degree. ... No one told me that there was funding for social work at that time. 
I only got to know about it when I was already studying education (Tshidi: black female, Bachelor of Education)

Tshidi's opportunities to make choices were, therefore, primarily limited due to her low social capital that contributed to her not accessing information from her school, peers and family connections on the funding options for a degree in social work. Lack of choices, therefore, disadvantages students, resulting in them failing to pursue their aspired goals. Nussbaum (2000) refers to this as adaptive preferences - that is, when individuals are deprived by circumstances and make choices resulting in their disadvantage.

Participation involves students influencing the real pedagogy, planning, and implementing the processes that work for them as a collective. There is evidence that participatory teaching methods enhance the learning processes of students who may need to acquire personal learning skills (Calitz, 2018). Using participatory teaching techniques, therefore, allows students to take part in their learning process and advantages them, as they are likely to perform better. Students are disadvantaged through traditional teaching methods where lectures are expected to deliver knowledge and students receive knowledge. However, participation in class is dependent on individuals' confidence and whether the environment is conducive. Lecturers should create environments that encourage all students to participate so that they become agents of their own learning.

\section{(d) Intellectual growth}

The intellectual dimension comprises capabilities associated with students' freedoms to gain knowledge, their ability to learn and think critically, educational resilience, and the way they reason to make decisions on matters that affect their lives before, during and after university. In the higher education context, Walker (2006) suggests that practical reasoning involves students' ability to reflect and build on their lives through critical and reasoned decisions. Wilson-Strydom (2015) also view this capability in the context of opportunities for students to make reasoned decisions as they complete schooling and enter university. However, this capability can be diminished in the face of unequal participation of students through the knowledge in-knowledge out 'banking system' of education (Calitz, 2018). The banking system in higher education is associated with methods that regard students as mere recipients of knowledge (Freire, 2006). For instance, Thandaza explains how critical thinking capability was diminished among some of the students through the teaching methods:

There are lecturers who just teach from the book and reproduce words exactly as they are used in the book. As a student I feel that I should understand a concept and apply it to different instances rather than taking it as it is from the book because we all know how to read. (Thandaza: black female, Honours in Business Studies) 
Failure to engage students and apply knowledge to real-life situations constrained the capability of critical thinking to develop among students; yet Nussbaum $(2002,2010)$ argues that this capability is instrumental in enhancing students' ability to critique unequal conditions. Concerning students' transition to university, knowledge capability relates to students being cognitively well-prepared by their schooling to gain university knowledge (Wilson-Strydom, 2015). Female students view education as empowering and enabling to get employment opportunities and the opportunity to bring improvement to their families and their communities (Walker and Loots 2015). The intellectual dimension also includes learning disposition, which refers to students having the 'curiosity and desire for learning'; students' ability to learn declines when their will to learn is low (Wilson-Strydom, 2015:120). Calitz (2018) stresses the role of students in having the necessary knowledge and skills to speak and participate in research. Because of the skills she gained from schooling, Ikhona was proactive and found it easy to adjust to university teaching:

It was necessary for me to change my attitude and the way I was studying because I felt that some of the lectures were not good. The lecturers did not teach the way we were used to in school. I realised that I was responsible for my learning and that I had to spend more time researching on my assignments and reflecting on what has been taught in class. (Ikhona: black female, Honours in Psychology)

Underlying the above is the personal determination to learn and to work hard. While being cognitively prepared to learn constitutes Wilson'-Strydom's (2015) knowledge capability, intellectual capability involves several aspects beyond one's preparedness and ability to learn. The intellectual dimension is valuable in that it incorporates various capabilities that would be used to assess students' opportunities to attain different forms of subject and professional knowledge, the ability of students to make reasoned decisions about their future, having the skills and willingness to learn and to conduct research independently, and to think critically about the knowledge they encounter in classes and in their everyday lives.

\section{(e) Socio-psychological and mental health}

Socio-psychological and mental health capability is significant in determining individuals' ability to do things they value (Robeyns, 2003; Wilson-Strydom, 2015; Calitz, 2018). Fear and anxiety diminish students' freedom to learn and participate in university activities during their first year of university (Wilson-Strydom, 2015). Partly because of the poor quality of schooling, first-year students often lack confidence; yet this capability is critical for learning to occur (Walker, 2006; Wilson-Strydom, 2015). Calitz (2018) also illuminates the capability of socio-psychological and mental health as associated with anxieties due to lack of resources for students to maintain their lives at university. In our study, for instance, Mamelo experienced stress when she failed the Food Sciences programme that she was initially studying before she re-registered for another degree programme: 
My elder sister who was at this university gave me hope when I failed my modules. I remember I went to her the first time when I failed my modules and I was crying. She told me that things were going to be fine and invited me to the church where I received spiritual support. I believe in the Lord and that everything is possible with him. This changed my life and encouraged me to reregister for Psychology (Mamelo: black female, Honours in Psychology).

Central to Mamelo's rebound was the social and spiritual support that she received from religious and social networks, which were valuable in her life. The significance of this capability is that the absence of socio-psychological and mental health compromises students' abilities to learn well, free of undue or extraneous stresses. The dimension emphasises students' abilities to have lives that are free from academic, financial, and social pressures. The dimension is significant for assessing whether students have the mental wellbeing and emotional freedom that enable them to focus on their studies.

\section{Discussion}

This paper demonstrates how the definition of (dis)advantage can be nuanced through exploring the different dimensions of students' wellbeing. It shows that the capability approach offers flexible spaces for interpersonal comparisons of student (dis)advantage through the proposed dimensions: affiliation, economic stability, autonomy and participation, intellectual growth, and socio-psychological and mental health. Therefore, (dis)advantage is complex and multidimensional and cannot be explained using race only when designing interventions. It is crucial to consider these dimensions in interventions when addressing inequalities in higher education so that diverse students have the same opportunities to access, participate and succeed in universities. Some of the interventions to consider include lobbying and engaging with people in positions of power on ways of reducing inequality within society, strengthening efforts to prevent racism through implementing awareness-raising programmes, punitive measures against perpetrators, and having more outreach programmes to change perceptions of racism in the communities. Building confidence and participation among the black students through adopting more interactive teaching methods and promoting them to participate in university social events can also be considered. This should be coupled with improving funding to all deserving students from low-income backgrounds and adequately catering for university expenses.

It is clear from the above capability-informed dimensions that students could be advantaged in one way but disadvantaged in another. The more students have the above capability dimensions, the more they are advantaged, while lacking one or more of these capabilities results in them being disadvantaged. Conversion factors such as unfriendly campus environments, poor schooling, and inability to fluently use the language of instruction constrain black students from having opportunities (capabilities) and agency to turn university resources 
into achievements (functionings) for their wellbeing; hence they become disadvantaged. It is thus necessary that structural impediments in wider society - including racism, inequality, and poverty - be removed.

Thus, students with cumulative disadvantages because of lacking some of the above capability dimensions are affected more; hence the need to implement strategies that consider clustered disadvantages in interventions. Advantaged students are likely to have most of the above capabilities dimensions and often experience 'fertile functioning', which helps them to have more attainments in their university education (Wolff and De-Shalit, 2007). It also needs to be emphasised that the above capability-informed dimensions of (dis)advantage are preliminary, which implies that a list of capabilities should be developed after consulting the students concerned in each context.

This paper illustrates that the capability approach enables us to measure interpersonal (dis)advantage for individuals as compared to families or communities (Robeyns, 2017) through focusing on students' real opportunities and how these are differently affected by structural, social and personal factors. Equally relevant is that the above conceptualisation of (dis)advantage allows us to understand student diversity and how their identity - that is, race, gender, and social class - intersect to form advantage or disadvantage (Robeyns, 2017). One can focus on the full range of capabilities and functionings individuals possess that affect their capacities to turn resources into achievements. Finally, by focusing on conversion factors, we can assess the barriers that inhibit students from achieving the things they have reason to value in education (Walker and Unterhalter, 2007). These are points that interventions should address. The capability approach is flexible in linking individual students with their socio-economic background, their relationships, and structural arrangement. Given the diverse nature of student bodies at universities concerning preparedness, social class and race, this approach offers an illuminating evaluative framework that can be applied to understand the multi-dimensionality in student wellbeing.

Overall, (dis)advantage can be evaluated by using the goals of higher education in South Africa as the adjudicating framework to establish the extent to which students have achieved the functionings related to what they value in universities. The respective capabilities are then extrapolated from the identified functionings reported by students. Three overlapping goals underpin policy in higher education, namely the need to produce skilled graduates for economic growth, personal development, and socially responsible citizens (Department of Education, 1997). When evaluating (dis)advantage, it is relevant to use these pillars as an adjudicating framework for evaluating the quality and outcomes of higher education. One of the goals of higher education is to prepare students for employment by equipping them with knowledge and skills for specific professions (Bok, 2006). Bok further states that universities should produce graduates who are creative and have critical thinking and communication skills. However, Walker and McLean (2013) comment that these goals are associated with the instrumental part of higher education that prioritises universities to produce graduates for economic growth. In this regard, Nussbaum (2010) criticises education models that are based only on economic growth models 
for failing to produce graduates who have the necessary critical thinking skills to participate in the political process in their countries, to recognise and respect citizens, and to think in a reasoned way about life. Universities should develop graduates who are not only knowledgeable but also empathetic, able to understand and value diversity and can fit into the global world (Nussbaum, 2002; Walker, 2006). Advantage is thus conceptualised as having the opportunities to achieve education goals, while disadvantage is having limited opportunities to do so. The implication of the above is that, for diverse students to attain more educational achievements (advantage), universities should provide them with the necessary opportunities and conditions of possibility of pedagogical arrangements to enable learning, university ethos and inclusive university activities and opportunities (university conversion factors).

\section{Conclusion}

As stated at the beginning of this paper, the concept of historically disadvantaged in higher education policy refers to black students, which means that the concept is racially defined. Nevertheless, this definition does not reveal the different opportunities in access and participation once students are enrolled at university. It ignores the intricacies of (dis)advantage in students' experiences. For example, the definition only tells us the number of black students who enrolled at university and who graduated, but this does not adequately reflect the different opportunities these students had to succeed. The capability approach helped us to understand how the distribution of opportunities varies between black and white students as a result of structural and institutional factors rooted in the history of the country and how these relate to individual and environmental factors that are both enabling and disabling to students. The capability approach, therefore, allows us to go beyond the surface to have a deeper understanding of (dis)advantage and hence offers a more robust and multidimensional approach for policy interventions. While we identified race as one of the factors (dis)advantaging students, there are other factors at play that influence (dis)advantage, such as social-economic status, social-psychological and mental health, participation and voice, intellectual voice, and other forms of affiliation. Through adopting an expanded definition of '(dis)advantage', policy should be able address all forms of exclusions (e.g. white female living with disabilities). It is worthwhile for higher education policy to shift from a simple, monodirectional definition of '(dis)advantage' in interventions to considering the different dimensions underpinning the term and how these dimensions interact to further improve or worsen students' lives.

\section{Acknowledgements}

This research was funded through the South African Research Chair Initiative of the Department of Science and Technology and the National Research Foundation of South Africa (grant number 86540). 


\section{Author Biographies}

Oliver Tafadzwa Gore holds a PhD in Development Studies and is a Post-doctoral research fellow at the Education and Human Rights in Diversity Research Unit of the North-West University. His research focuses on wellbeing of students, diversity and inclusivity in higher education. His interests are on addressing inequality and promoting social justice in higher education.

Melanie Walker is a distinguished professor at the University of the Free State and SARCHI chair in higher education and human development.

\section{References}

Bathmaker, A. M., Ingram, N. and Waller, R. 2013. Higher education, social class and the mobilisation of capitals: recognising and playing the game. British Journal of Sociology of Education, 34(5-6): 723-743.

Bok, D. 2006. Our Underperforming Colleges: A Candid Look at How Much Students Learn and Why They Should be Learning More. New Jersey, Oxford: Princeton University Press.

Bourdieu, P. and Passeron, J. 1977. Reproduction in Education, Society and Culture. London: Sage.

Bozalek, V. and Boughey, C. 2012. (Mis)framing higher education in South Africa. Social Policy and Administration, 46(6): 688-703.

Calitz, T.M.L. 2018. Enhancing the Freedom to Flourish: Participation, Equality and Capabilities. London: Routledge

Cleaver, F. 2007. Understanding Agency in Collective Action. Journal of Human Development, 8(2): 223-244.

Council on Higher Education 2004. South African Higher Education in the First Decade of Democracy.

Council on Higher Education 2018. The National Plan for Higher Education (2001) targets: Have they been met? Council on Higher Education: Pretoria.

Department of Education 1997. Education White Paper 3: A programme for the Transformation of Higher Education. Pretoria: Government Gazette, 386 (18207).

Department of Education 2006. Funding for foundational provision in formally approved programmes. Letter to all higher education institutions in South Africa. Department of Education: Pretoria.

Leibowitz, B. and Bozalek, V. 2015. Foundation Provision, - a social justice perspective Part 1: A leading Article. South African Journal of Higher Education, 29(1): 08-25

Loots, S. and Walker. M. 2015. Shaping a gender equality policy in higher education: Which human capabilities matter? Gender and Education, 27(4): 361-375.

Mathebula, M. 2019. Recognising poor black youth from rural communities in South Africa as epistemic contributors. Critical Studies in Teaching and Learning, 7(1): 64-85. DOI:10.14426/cristal.v7i1.181 
Mutanga, O. and Walker, M. 2015. Towards a disability-inclusive higher education policy through the capabilities approach. Journal of Human Development and Capabilities, 16(4): 1-17.

Nussbaum, M. 2000. Women and Human Development. Cambridge: Cambridge University Press. Nussbaum, M. 2002. Education for Citizenship in the Era of Global Connection. Studies in Philosophy and Education, 21(4/5): 289-303.

Nussbaum, M. 2010. Not for Profit: Why Democracy Needs Humanities. New Jersey: Princeton University Press.

Rawls, J. 1971. Theory of Justice. Cambridge MA.: Harvard University Press.

Robeyns, I. 2003. Sen's Capability Approach and gender inequality: Selecting relevant capabilities. Feminist Economics, 6(1): 93-114.

Robeyns, I. 2017. Wellbeing, Freedom and Social Justice. Cambridge: Open Book Publishers.

Sen, A. 1984. Resource Values and Development. Basil Oxford: Blackwell Publisher Ltd.

Sen, A. 1992. Inequality Re-examined. Clarendon Press: Oxford.

Sen, A. 1999. Development as Freedom. New York: Knopf.

Soudien, C. 2010. Affirmative action and admissions in higher education. South African Journal of Higher Education, 24(2): 221-223.

Statistics South Africa. 2020. Unemployment rate among youth is higher irrespective of education level. South Africa. Available at: http://www.statssa.gov.za/wpcontent/uploads/2019/05/Youthdatastorygraph.jpg (accessed 7 June 2020).

Therbon, G. 2013. The Killing fields of inequality. Cambridge: Polity Press.

University of the Free State. 2017. Integrated Transformation Plan. University of the Free State. Available at: https://www.ufs.ac.za/docs/default-source/all-documents/the-ufsintegrated-transformation-plan.pdf?sfvrsn=9752a521_0. (accessed 17 January 2020).

University of the Free State. 2018. Anti-Discrimination, promotion of equality, and social justice policy and procedures (June 2018). Available at: https://www.ufs.ac.za/docs/defaultsource/all-documents/ufs-anti-discrimination-policy_councilapproved.pdf?sfvrsn=f33 dbe21_0 (accessed 10 January 2020)

Walker, M. 2006. Higher Education Pedagogies: A Capabilities Approach. Berkshire: Open University Press.

Walker, M. 2016. Context, complexity and change: Education as a conversion factor, Race, Ethnicity and Education, 19(6): 1275-1287.

Walker, M. and Fongwa, S. 2017. Universities, employability and human development. London: Palgrave Macmillan.

Walker, M. and McLean, M. 2013. Professional Education, Capabilities and the Public Good: The Role of Universities in Promoting Human Development. London: Routledge.

Walker, M. and Unterhalter, E. 2007. Amartya Sen's Capability Approach and Social Justice in Education. New York: Macmillan.

Wilson-Strydom, M. 2015. University Access and Success: Capabilities, Diversity and Social Justice. New York: Routledge. 
Wilson-Strydom, M. and Okkolin, M. A. 2016. Enabling environments for equity, access and quality education post-2015: Lessons from South Africa and Tanzania. International Journal of Educational Development, 49: 225-233

Wolff, J. and De-Shalit, A. 2007. Disadvantage. Oxford: Oxford University Press. 